\title{
Introducing Dentistry 3000
}

Alexandre R. Vieira

Editor in Chief, Dentistry 3000

Department of Oral Biology, University of Pittsburgh, School of Dental Medicine, Pittsburgh, PA, USA

A few decades ago, scientific journals were housed at university libraries, which handled the journal's peer-review process and production. When universities faced economic hardships and library budgets were cut, one solution was to allow publishers take over journal responsibilities. Most of the revenue came from readership subscriptions. More recently, subscriptions have been under attrition and the model of charging author fees for publication has emerged. Parallel to these events is the surge of the World Wide Web and the possibility to publish scientific papers as online only. Furthermore, publishers raised fees for online-access to scientific literature. Publishers charge around US\$35 for access to each individual paper they publish.

Online-only scientific journals became an attractive business, with some companies holding more than 200 journals each and charging author fees from US $\$ 300$ to more than US $\$ 2,000$. The quality of these journals has been questioned and evidence suggests that the quality of the published papers is lower than other more reputable journals.

For dental research in particular, opportunities to publish high quality research in highly visible journals can be limited, despite the fact that more than 2,000 dental journals exist. To provide a venue for the dental community that is peer-reviewed, open access with no cost to readers, and free of charge to authors, we created Dentistry 3000 . The first issue includes five papers, one on the association of cleft lip and palate with interferon regulatory factor 6 , one on the association of cancer with cleft lip and palate, one on the relationship of tooth and facial dimensions, one on the heritability of facial structures, and one summarizing the proceedings of the cariology symposium during the International Association for Dental Research 2012 meeting.

Dentistry 3000 is published by the University Library Systems, University of Pittsburgh, as part of its D-Scribe Digital Publishing Program, and is cosponsored by the University of Pittsburgh Press.

This work is licensed under a Creative Commons Attribution 3.0 United States License.

This journal is published by the University Library System, University of Pittsburgh as part of its D-Scribe Digital Publishing Program and is cosponsored by the University of Pittsburgh Press. 